\title{
Emotional Reflexivity and Leader Effectiveness
}

\author{
Kpakol Aborlo Gbaraka ${ }^{1}$, Isaac Zeb-Obipi $\mathrm{PhD}^{2}$ \\ ${ }^{I}$ Department of Management, Rivers State University of Science \& Technology, \\ Nkpolu-Oroworukwo, Port Harcourt \\ ${ }^{2}$ Department of Management, Rivers State University of Science \& Technology, \\ Nkpolu-Oroworukwo, Port Harcourt
}

\begin{abstract}
Organizations comprise of ordered task arrangements and relationships geared towards the achievement of specified objectives. The success of such arrangements and relationships are most often premised on the effective motivation of members, interaction between members, and the resilience of the leader. In this study we argue, that given the social context the organization affords its members and the diverse groups which comprise those contexts, the effectiveness of leadership would be based on its ability to meet the expectations of its followers. One way this can be achieved is through emotional reflexivity which entails the practice of reflection, morphing and alteration of emotions or emotional states as a means of adapting to situations and the expectations of social groups. We first reviewed literature on the concept of the variables, and thereafter the role of emotional reflexivity in terms of emotional experience, identification and display on the effectiveness of leadership. In conclusion we found that emotional reflexivity affords leadership a more flexible approach towards social issues and relationships.
\end{abstract}

Keywords: Emotional reflexivity, emotional identification, emotional experience, emotional display, motivation, relationship, resilience, leader effectiveness.

\section{Introduction}

Leadership is about influence and the coordination of group or organizational effort. As a social action, it charts the organization's course by providing exemplary behaviour and by purposively integrating various organizational facets through the implementation and instituting of function-specific regulations and policies. Going by this, it suffices then to state that leadership is first, goal or objective oriented and second, people oriented. In assessing leader effectiveness, Yukl (2011) argued that it is primarily a function of the evaluation of leaders by followers with regards to levels of cooperation, group cohesion and the production of change and movement. This view is shared by Reave (2005) who opines that leader effectiveness relates to outcomes such as follower retention, follower satisfaction with leadership and follower recognition of and deference to leadership. These descriptions of leader effectiveness imply a rather subjective approach to leadership based on the perceptions of the followers or subordinates. Therefore, one can assume that a proper assessment of leader effectiveness should consider antecedents which embody the alignment, alteration, or morphing of individual states such as emotions or behaviour in line with the "general expectations" of followers.

According to Enwurum (2007), leadership in most Nigerian public sector organizations contends on a daily basis with challenges emanating from unionism, opposing informal factions and cliques, political-based interventions which undermine leader authority in administrative processes and insubordination as a result of assumed political ties or dominant group affiliations. However, Njoku (2004) noted that the presence of opposition should not be considered a problem to leadership rather, the inability of leadership to unite differing positions through the identification and treatment of key contention areas either through collective bargaining activities or through vivid communication of purpose or intent to interested parties .Hence, the actual problem then can be considered as emanating from leadership's aloofness and poor emotional reflexivity in its relationship with the various organizational stakeholders of most Nigerian public service ministries.

Emotional reflexivity refers to the process of reflecting upon and acting back upon one's emotional state in response to a social experience. By virtue of emotional reflexivity, the individual is able to observe and regulate emotions in such a way that allows for modifications or alterations for suitability with external events or situations. Rosenberg (1990) opined that reflexivity holds significant implications for the emotions in at least three key aspects. First, in emotional identification: where reflexivity serves as an interpretative process. Second, in emotional display: where reflexivity is concerned with self-regulation and emotional amiability aimed at producing desirable outcomes with regards to working with people and producing intended effects in their minds. Third: in the production of emotional experiences: where reflexivity is utilized as a tool in the creation of internal states of arousal.

We find in extant literature a myriad of studies which have examined the relationship between emotional intelligence and leadership effectiveness, even in Nigeria. However, we argue that emotional reflexivity varies significantly from emotional intelligence especially in the area of emotional enactment as a 
result of intersubjectivity (Ohman et al., 2001; Williams et al., 2004; Keltner and Kring, 1998). Whereas emotional intelligence concerns itself with the understanding of self and the emotions of others, the construct of emotional reflexivity focuses on emotional alterations and representations presented as a result of the individual's interactions and social experiences with others. It (emotional reflexivity) embodies the reflective dialogue with oneself based on social encounters and the production or morphing of emotional states considered suitable and appropriate in creating desirable effects in others. So where emotional intelligence is concerned with an understanding of self with the intention of building emotional capacities for relating better with others, emotional reflexivity is concerned with understanding others with the intention of redefining self for effectiveness. This paper therefore contributes to an observed literature gap in the study of leader effectiveness, given the lag in literature which addresses emotional reflexivity as a factor which can be considered as an imperative for leader effectiveness.

Our purpose in this paper is threefold. First we address the definition and conceptualization of the variables of the study: emotional reflexivity and leader effectiveness. Second, we theoretically assess the possible connection or association between the variables and the implications of such for Nigerian public organizations, and third, we proffer conclusions and recommendations based on the findings of the study. Our review of the relationship between emotional reflexivity and leader effectiveness is premised on the theoretical framework of the intersubjectivity theory (Grant \& Osanloo, 2014), which Jacob (1992:7) describes as suggesting that:

We develop firm, responsive, flexible self-structure (or processes of self-regulation) through identifying with, articulating and integrating our emotions, and that others serve self-object needs to the extent that they forge an empathic tie with us through which we are aided in the process of emotional integration.

This forms the basis of our argument in this study and as emphasized by Zeb-Obipi (2016) offers the map for our line of thought.

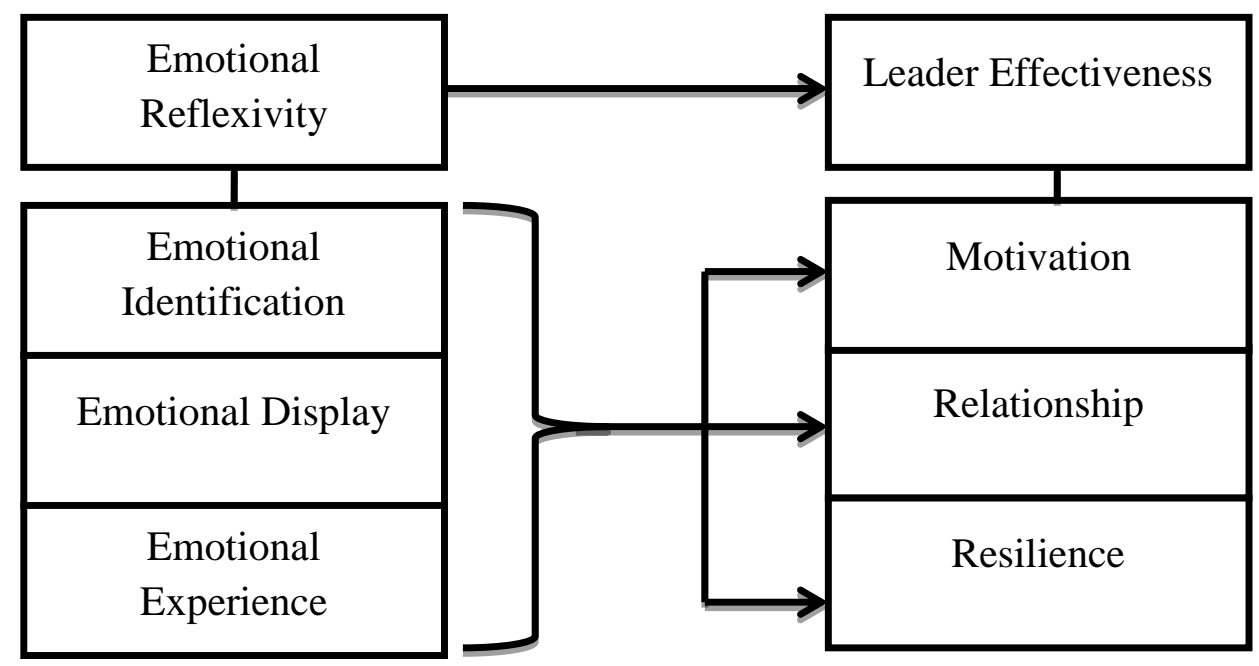

Figure 1: Conceptual framework of the study

Source: Researchers' desk

\section{Reflexivity}

The concept of reflexivity varies in meaning in relation to the context of usage. In sociological methodology, reflexivity can be described as referring to the actual participation and personalized experience of social phenomena by the researcher in ways that allow for understanding and knowledge generation through interaction with the object. However, as earlier pointed out, our focus in this study is on the alteration of emotional states as a result of experience and the general expectations of others, hence we are more inclined to view reflexivity in line with the definition put forward by Flanagan (1981) as being the decisive evidence of the ability of the individual for self-examination into their own states or conditions. This reiterates the description presented by Warwick (2011) that reflexivity is concerned with the paying of attention and the engagement of experience as well as the close observation of one's thought over an extended period of time.

From the above descriptions, we draw seven main factors or aspects which we believe characterize the practice of reflexivity, namely: self-examination, self-consciousness, attention, experience, thought, and selfengagement. These offer an imagery of the reflexivity as embodying both process and outcome in the sense that one is first conscious of his or her conditions, reflects upon the experiences produced by those conditions and thereafter enacts responses which are considered adequate in addressing the conditions. Hence, we define 
reflexivity as the behaviour in which an individual alters his (her) state to conform with conditions produced from his (her) interaction with others. According to Peters (2013) reflexivity is the very essence of consciousness. The capacity for awareness, thought and of the close observation of behaviour, are defining factors of the state of consciousness. Resulting actions and behaviour are considered as subjective and as mirroring the effects of the external. Similarly Bauer et al. (2011) opined that with regards to reflexivity, change is not only apparent in behaviour, but also apparent in the motivational substance from which such behaviour emanates. Therefore it is not only a change in the actions or attitude of the individual in response to experiences, but a change in the way such individuals perceive and understand themselves to be within the context of the interactions which produced such experiences.

Weaver (2013) argued that each relationship or interaction between two or more people comprises of certain irreducible properties which is a product of the reciprocal orientation of the parties or individuals involved. Hence the individual's behaviour or action is most often not based on personal concerns alone but is also concerned with what can be referred to as the "relational goods" (trust, reputation, mutual concerns etc.) of the relationship. This argument formed the basis for Donati's (2011) development of the relational theory of reflexivity in which he relates the experiences of individuals and the methods or means through which they address their differences as well as the expectations of the social network to which the belong. First is the issue of self-consciousness entailing internalized discussions with self and reflection on actions (personal reflexivity); then second, the modification of emotions, behaviour or attitude to fit into the social framework, tolerant of views held by the elements which populate one's social network (relational reflexivity).

We have in this section examined the meaning of reflexivity as it applies to this study. We differentiated between reflexivity as a phenomenological method in social research and as behaviour in social interactions; an outcome which further ingrains the activities of the study within the earlier specified theoretical framework of intersubjectivity. Our intent for this expatiation on the concept of reflexivity is to provide a clear description of what it denotes within this study and the implications of such with regards to leaders emotions and their effectiveness, as we yet intend to discuss.

\section{Emotional Reflexivity}

In introducing this paper, we earlier described emotional reflexivity as being concerned with the process of reflecting and acting on one's emotional dispensation or state in response to social experiences. Rosenberg (1990) noted that the internal constituents from which emotions spring are fundamentally physiological and comprise of the autonomic nervous system and of the functioning of certain parts of the brain. Therefore, reflexivity affords the human emotional reconfiguring process which arouses new states of being and conditioning which are thereafter separated from the physiological. According to Holmes (2015), emotional reflexivity refers to the intersubjective interpretations of one's emotions and those of others as well as the corresponding enactment of each. Within the framework of the intersubjectivity theory, it emphasizes on what can be described as "the emotional etiquette" in social relations and prescribes appropriate emotional conditionings or dispensations suited for emerging situational variety.

Rosenberg (1990) asserted that within social networks and the constructions of social reality, certain expectations hold true with regards to the causal connections between stimulus situations or events and emotional outcomes. Such expectations follow that insults should lead to anger; threats are expected to generate fear; while compliments are expected to arouse emotions of pleasure or happiness. Arguing further, Rosenberg insists that these causal connections constitute a broader system which can be viewed as the emotional logic of the life world within which the individual functions and socializes. Such emotional logics are most often considered necessary based on their development and socio-inherent acceptance as norm across varied social constructions of reality.

We previously identified three ways in which, according to Rosenberg (1990), emotional reflexivity comes to bear. These we stated comprise of emotional identification (the process of determining our feelings and emotional state), emotional display (the process of self-regulation and consciously adapting or morphing our emotions), and emotional experience (the control of our experiences of these emotions through the production of effects on our bodies and mind). These, as Hammer and Reymen (2002) observed, provide a dimensional basis in the assessment of emotional reflexivity.

Emotional Identification: According to Rosenberg (1990), the emotional identification of the individual is a consequence of three key factors, i) the causal assumptions: in which emotional states are considered as outcomes of one's interactions within a specific social framework, and is accepted based on the logic behind its antecedent (e.g. anxiety as a result of uncertainty; ii) cultural scenarios: where emotions are matched and compared to various societal paradigms (e.g. love and how it is defined) and social values which provide the criteria for evaluating one's emotions; iii) and social consensus: which describes the situation in which emotions are considered outcomes of the responses of other people to the shared circumstances or events (e.g. laughing at jokes because others are laughing). 
We find in Rosenberg's position, strong argument in support of cognition as a determining factor of emotional states, but this is disputed by Petty et al, (2003) who argued that the emphasis on cognition as a determining factor of emotions, affections and attitudes is rather flawed, this is as various aspects of personal belief systems and values could also be considered integral in the identification of emotional states. However, we tend to agree with Rosenberg's (1990) position on cognition and emotional identification on the basis of Usó-Doménech and Nescolarde-Selva (2016:1) assertion that:

Every human being has a belief system that they utilize, and it is through this mechanism that we individually, "make sense" of the world around us... A significant can nevertheless be iconic in a belief context and, to be symbolic in another context. From these we can see that people are capable of constructing all manner of individual beliefs by which they tell stories about how the world works. As humans, we tend to use all these belief systems to varying degrees to cope with events in our lives. Ultimately we need the world to make sense at some level. Therefore, those areas where that "sense of reality" is most challenged will tend to be the areas in which the most controversies exist.

Emotional Display: This is described as comprising of both the exhibition and the concealment of emotions. As an interpersonal effect, its objective is to purposively create or produce intended outcomes in the phenomenological worlds of other people (Rosenberg, 1990; Hammer and Reymen, 2002). Rosenberg (1990) opined that individuals engage in emotional display as means of effectively navigating through the maze of various emotional norms, structured by society and afforded moral justifications based on implied meanings. This is to say, individuals are expected within various social frameworks to portray or exhibit certain types of emotions in response to various kinds of situations or events. A good example would be the expression of grief or sadness at the news of a relative's death, or the expression of gratitude at the receipt of a gift. The failure to exhibit emotions considered as suitable with respect to related incidences or circumstances usually creates the impression of one as being sordid or morally reprehensible.

Given the moral implications of such alterations or morphing of emotions into desirable or expected states in spite of actual personal feelings or opinions about issues, some may argue that on the basis of its tendency for falsehood and manipulation, it provides a rather Machiavellian ingredient and vice into social relationships. On the contrary, we believe such assumptions are in error. Our argument follows that sustained social relations are premised on social actions. Man is both a mindful and minding being, in which his activities and choices are often premised on the subjective assessments and consideration afforded the presence and opinions of others (Zeb-Obipi, 2007; Ahiauzu \& Asawo, 2016). We find support for our position in the intersubjectivity theory within which this study is framed, and its emphasis on the requisite of behavioural enactments for effective social functioning and relations.

Emotional Experience: This is concerned with the involuntary emotional states which are inadvertent and appear to be beyond the control of the subject. Such experiences, although based on external events, are however produced and sustained by thought and also by the body (Rosenberg, 1990). McCullough et al, (2004) observed that emotional experiences have powerful and even long lasting effects on the consciousness and wellbeing of the individual. This is especially true in the case of moods which could translate overtime into feelings of despair and depression. This is as Rosenberg (1990) opined that given the implications of such emotional effects on the individual and the implications of such on his or her functionality within the society, there is therefore the need for self-regulation. Such control measures or self-regulation would seek to first identify the emotion triggering and sustaining sources which as Rosenberg (1990) observed is linked to the thinking pattern and the stimulus events that give rise to the cognition. That is to say, one can alter emotional experiences by paying attention to one's thoughts or by what Rosenberg (1990) referred to as selective stimulus - deciding to avoid situations, people or things that upset or trigger unhappy and undesirable emotions.

It is important to note that although emotional experience and emotional display appear similar, there exists significant difference between both dimensions. While emotional experience focuses on involuntary and inadvertent internalized states which are results of external stimuli and encounters, emotional display is concerned with voluntary emotional states and the expressions or exhibitions of such based on context or situation. We find that all three dimensions (emotional identification, emotional display and emotional experience) appear to be connected and dependent on each other. This is as the transition or morphing of emotional experiences into displays must first begin with the identification ofits undesirable state or unfitting nature and the need for such alterations. We have in this section examined emotional reflexivity and its conceptualization. We find that emotional reflexivity which is primarily concerned with consciousness and the reflection on emotional states as well as the alteration of such is premised on three functions: emotional identification, emotional display and emotional experience. We have also argued that although these dimensions may appear similar, they are distinct and entail unique dimensional qualities through which emotional reflexivity can be evaluated and operationalized. 


\section{Leader Effectiveness}

This section of the paper examines leader effectiveness and its conceptualization as earlier proposed. Our intent here is to offer a description of the variable: leader effectiveness as it is applied within the context and theoretical framework of this study. The conceptualization and descriptions provided would offer vivid clarifications as regards our position on leader effectiveness and also facilitate a more coherent theoretical discourse of its consequential relationship with emotional reflexivity within the context of Nigerian public organizations.

First, what is leadership? Leadership is described as a social influencing process in which one, whether elected, appointed or by duress, obtains power to either motivate or coerce others towards the attainment of particular objectives. Such a definition, we argue would apply within a broader spectrum which captures sovereign National or military related events, however within the streamlined realities of the business organization, we are more inclined towards the definition put forward by Njoku (2008) that leadership is the process of influencing and affecting people such that they are enthusiastic and willing to work with the leader in the attainment of organizational goals and objectives. It is as Inyang (2004) observes that leadership "carries the people along" and draws its essence from the validations afforded it by the people it supposedly leads.

Ogbeidi (1997) argued that leadership should embody integrity, selflessness, vision and prudence. The specifications of these attributes throws weight behind the personality trait theories of leadership, which considers prerequisites such as level-headedness, virtue and other ethical factors as benchmark for leader capacity or qualification, but as Urim (2009) observed, the ascription of personality traits or unique elitist statuses to leaders is highly flawed and fails to take into account situational factors. In Cole's (2000) view, the key function of leadership is persuasion. It is concerned with inducing and sustaining followership through a combination of strategy, character and will. This emphasizes the centrality of the people-factor in the assessment of leadership and its effectiveness, stressing the position of the followers as key in the choice and decision of whom and what should constitute leadership and how effective it is rather than preconceived traits or character attributes. This opinion is reiterated by Njoku and Nwakwuribe (2014) in the assertion that:

Leadership involves other people-employees or followers who by their willingness to accept directions from the leader, defined the leaders status and make the leadership process possible. Thus without people to lead, all the leadership qualities of a leader would be irrelevant.

The implication of the above statement is that, much of what can be considered as good or bad, successful or failed, effective or ineffective leadership is hinged on the subjective opinion of the majority of the people being led. It is therefore in place to argue that organizational leadership dwells substantially on the shoulders of the acceptability of the followers rather than any idealized personality trait or assumed sense of morality, ethics or principles. Hence, leader effectiveness is basically interactional and relies on the rather tentative nature of the expectations of followers.

Several definitions of leader effectiveness exist. Some scholars have examined the variable based on the achievement of organizational goals (profitability, market share, growth); others have examined leader effectiveness based on the subjective assessment of subordinates, superiors, followers and peers. While others have rather examined the variable based on its effect on followers and its capacity to endear loyalty and maintain authority. Our position on leader effectiveness is in line with that put forward by Yukl (2011) and Cole (2000) that the variable is highly subjective and usually framed based on the social context within which the leader functions and is operational.

Therefore we define leader effectiveness as the subjective assumptions held by followers, peers and superiors about the capacities, behaviour and abilities of the individual who is presumed to head the group, team or organization. Our definition is thus premised on three key assumptions of the leader: first are capacities which relate more to the perceptions significant others hold about the leader's emotional, cognitive and intellectual capabilities. Second is behaviour which relates to the leaders actions and expressed attitudes towards others, and third is abilities which relates to the skill-set, competencies and work experience of the individual. Our definition reiterates previous descriptions of leader effectiveness by some studies (Reaves, 2005; Yukl, 2011, Hogan \& Kaiser, 2005; Njoku \& Nwakwuribe, 2014) which operationally measure leader effectiveness based on the perceptions held by significant others with regards to motivation, maintenance of considerably healthy relationships at the workplace and also being resilient.

Motivation: According to Deci and Ryan (2000), motivation can be described as the establishment of behaviour which is goal-oriented. It is concerned with the encouragement offered people which stimulate in them the desire to achieve stipulated individual, group and organizational goals which are interwoven in such a manner that the pursuit and achievement of one invariably connects to the achievement of the other. Watkiss (2004) opines that the key to motivation can be considered as either the prospect of a reward after achievement or the possibility of consequences as a result of failure. The ability of leaders to stir, energize and direct their followers is a function of two factors: first, the confidence the followers have in the leader as being competent and second, the respect followers have for the leader as a person of repute or experience. These are also a 
function of the perception of the leader held by the followers in which Yukl (2011) observes that the relationship between followers and leaders is usually based on mutual respect. When followers perceive their leaders as trustworthy and sincere, they tend to reciprocate with loyalty and commitment.

Relationships: The maintenance of healthy and cohesive groups or teams is also a criterion used in the measurement of leader effectiveness (Kaiser et al, 2008). This is as Njoku (2008) argue that leader effectiveness is based on the ability of leadership to provide the necessary platform upon which followers or subordinates can relate to group goals. It is important to note that in our assessment of group performance and teamwork as measures of leader effectiveness, our concern is placed on the prevailing state of collaboration, communication and interpersonal relations rather than the achievement of profitability and productivity. This is because we find that organizations may achieve growth, profitability and market share but at the same time be faced with challenges of insubordination, social loafing and poor work attitudes. We argue that the premise of leadership is followership which should be cohesive and comprise at considerate levels, willing and committed members. Our view of the leader and the benchmark for effectiveness is best captured in Okafor (2013: 285) statement that:

A leader is generally a person in a group who has influence on the group's activities and beliefs. He is the one who initiates action, gives orders, makes decisions, settles disputes between members and makes judgments. He is also the person who dispenses approval and disapproval, offers encouragement, serves as an inspiration and is in the forefront of any of the group activities. These functions enumerated are merely examples of the general influence or functions the leader exerts over the group. However, any particular leader may not perform all these functions, but to be a leader, he must perform many of them.

We argue that variables such as productivity, profitability and organizational growth are rather measures of organizational effectiveness and not leader effectiveness. When leaders are effective, followers are aligned and positioned in such a manner that facilitates organizational effectiveness.

Resilience: This refers to the leader's ability to anticipate and plan for conflict or other forms of perturbation. It is also concerned with the extent to which the leader is considered to be flexible, adaptable and accommodating (Madni, 2007; Umoh et al., 2014). Resilience in leadership is a reflection of the leaders experience and understanding of circumstances as well as the knowledge of what behaviour or action is best suitable to undertake in each unique or recurring circumstance. It denotes a sense of direction and consistency. It facilitates continuity and also enhances followers trust in the leader. Fletcher and Sarkar, (2013) describes it as comprising of two main concepts - adversity and positive adaptability. Adversity here refers to the possibility (impending) or presence of oppositions, unwelcomed interference and undesirable change effects (in the sense of uncontrollable disruptions to work processes or systems e.g. the spread of an epidemic, politically instigated violence etc.) which may pose as challenges and setbacks for leadership, while positive adaptability refers to the tendency for leaders to be flexible and to be able to adjust themselves (emotionally and behaviourally) in line to the changes and challenges of their external environment.

So far, we have defined and examined the conceptualizations of the variables of this study (emotional reflexivity and leader effectiveness). This has enabled us to first, understand the concepts and characteristics of the variables; and second, clearly demarcate between the connotative usage of the variables and how it is applied within the context of the intersubjectivity theoretical framework of this study and the functionality of both variables within the context of Nigerian public sector organizations.

\section{Emotional Reflexivity and Leaders Effectiveness}

Njoku and Adindu (2014) assert that the performance and viability of public sector organizations depends significantly on the effectiveness of the leadership. Leadership within the public sector is one which entails a higher level of relativity with regards to followers' expectations and extraneous variables. Several studies have consistently pointed out that leadership within the public sector is exposed to constant work related rivalry, heavy politicking, union activities, Government interference in the affairs of running the organization, informal group bickering and workplace clique activities at levels that are most often unhealthy and destabilizing. Unlike leadership in private sector organizations which wield substantial control over their staff and business affairs, most public sector organizations in Nigeria are driven by political mechanisms and their affairs hinged on the interplay of external contingencies (Enwurum, 2007; Njoku, 2008). The situation is such that requires the apt balancing of task functions with social relations in such a manner that while goals are being pursued, relationships are being maintained (Stoner et al, 2000; Njoku \& Adindu, 2014).

Njoku (2008) observed that most Nigerian public sector organizations especially public tertiary institutions are fraught with the activities of partisan politics and meandering decision making processes due to the challenges posed by various work unions and student groups which continually frustrate and thwart the efforts of leadership within these organizations. Here Wilson (2004) argues that leadership should have the capacity for conscious and non-automated responses to situations. This approach is one which does not rely on existing schemas or outlined procedures of how to address issues but learns to think and respond based on the situation. This is in line with Pearce \& Conger's (2003) observation that most leaders are ineffective as a result 
of habitual sense making and acquired automated-response patterns given occasions of their failure to distinguish between technical challenges - which have been experienced before and can be formatted to current schemas - and adaptive challenges - which present complex and multi-faceted issues often posing a problem to work structures, role expectations and poise. Such adaptive situations can be stressful, disorienting and most often rely on the leader's ability to connect with, convince and encourage followers to carry out functions or engage in activities in which their opinions or views may differ from that of the leader.

Nagata (2005) asserted that emotional reflexivity can be considered the medium through which leadership "learns in the event" and not "outside the event". This means, leadership through reflection and selfregulation can re-examine its own values and stress points, ascertain and identify its own worries, fears and assertions, consider alternatives and compromises, determine possible loses and advantages, all as a discourse with self even while engaged in the situation and based on these, come up with a more informed solution to the issue. However, as we earlier opined, emotional reflexivity is concerned with the morphing and enactment of emotions based on its "suitability" to the context of social interaction or event, therefore such discourses with self should be in reference to the state or nature of the social interaction in which the individual is engaged. Likewise Childre and Cryer (2000) opined that most times leadership fails in its bid to unite groups or differing opinions because of its prejudiced opinion and bias towards such groups. Such bias and negative feelings about others have a strong tendency of taking over one's emotions, resulting in anger, frustration and resentment during conflicts. Nagata (2005) identified diversity, especially cultural and ethnic, as a major platform upon which leadership conflicts spring from. In addressing this she emphasizes on the role of intercultural communication and in the enhancement of workplace relations and asserts that:

In the Arc of Projection one acts in the world without realizing the assumptions, biases, and prejudices one is projecting into the situation that is the context for one's action. In the Arc of Reflection, there is the opportunity to consider the results, to analyse one's own biases and prejudices, and to prepare for ongoing work in the world. This is certainly a recognizable cycle for interculturalists (p. 142)

In describing the role of emotional reflexivity and its positive impact on relationships, Nagata (2005) draws extensively from Hans-Georg Gadamer's hermeneutical circle about the arc of reflection and projection. According to Nagata (2005), the power of the process is in the flow and cyclic cause-effect relationship between reflection and action given the patterns of thought, feelings and behaviour in social interactions.

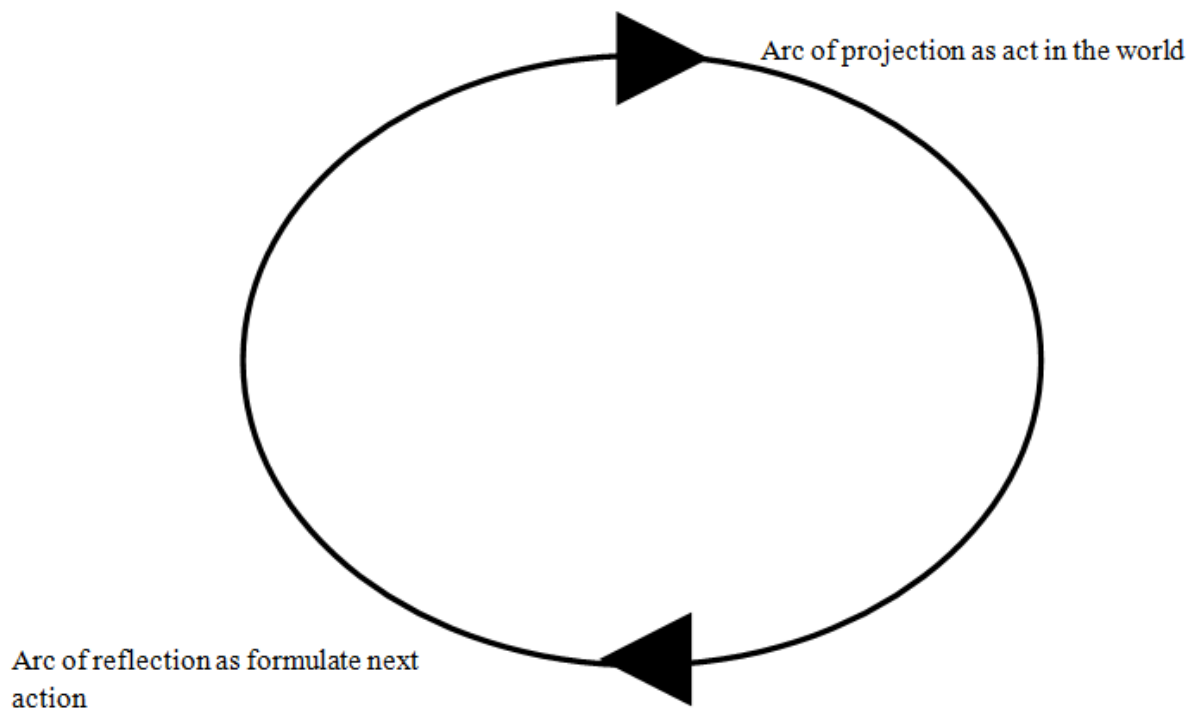

Figure 2: Hans-Georg Gadamer's hermeneutical arc of reflection and projection

We reiterate the opinion of Nagata (2005) in our argument for emotional reflexivity in leadership especially in her identification of communication as a harmonizing tool through which differing views or opinions can be synthesized. We argue that failure in leadership is not based on the non-actualization of stipulated organizational goals or objectives (such as profit and sales) but rather on the persistence of disharmony and continued rivalry between group members as well as between followers and leaders. We argue that the fundamental criterion for evaluating leader effectiveness and success should be based on the capacity of such to motivate followers, create cohesive workplaces and harmonious working relations, and also to be resilient in the face of challenges. Our assertion corroborates that of some scholars (Yukl, 2011, Njoku \& Nwakwuribe, 2014; Pearce \& Conger, 2003) which emphasize on leadership as being a function of followership. Its validity and authority is therefore premised on the "agreeability" of its followers and the consensual subjugation of individual will to that of the group as charted by the leader.

DOI: 10.9790/487X-1903026068 $\quad$ www.iosrjournals.org $\quad 66 \mid$ Page


We therefore argue that leadership within Nigerian public sector organizations, when it is emotionally reflexive would emphasize on collaboration and the settlement of dispute though understanding and compromise rather than enforced will or "silencing of opposition". This would suggest inclusivity in leadership and transparency. The ability of leaders to align or morph emotions in line with the changes in social context would also entail good understanding of the reason behind the other party's choice and the selective as well as wellthought out approaches towards convincing and persuading the other party to act in accordance with the leaders will or position, for to understand is to control.

\section{Conclusions and Recommendations}

In this study we examined the connection between emotional reflexivity and leader effectiveness in Nigerian public sector organizations. The study was as a result of the growing concern over problems of dispute, union strike actions, as well as unhealthy conflicts and rivalry which continue to undermine the efforts of leaders especially in Nigerian public sector organizations given the diversity of its interest groups and the level of influence exerted by each in the functionality of the organization. We argued that leader ineffectiveness in these organizations is as a result of its unresponsive and rigid nature; its prejudiced approach and automated treatment of these interest groups based on habitual sense-making, and its failure to motivate followers and achieve cohesion within the workplace.

We argued that the position of emotional reflexivity in the leadership of Nigerian public sector organizations is one which cannot be overemphasized. This is given the seeming overlap of the interest of these various internal and external groups in the affairs of the organization. In our view, the presence of oppositions and diversity should not be considered problematic but rather should evidence and reflect the democratic nature and tolerance of leadership for difference in opinions which can be harmonized through communication and understanding. The study offered insight with regards concepts such as emotional identification, display and experience, which were examined as dimensions of emotional reflexivity and also measures of leader effectiveness such as motivation, relationship and resilience. Our evaluation of the relationship between the variables also revealed the role of communication in the assessment of leader effectiveness especially with regards to the harmonizing of opinions and views. We find that apart from emotional reflexivity, effective communication also presents itself as the gateway through which leadership can express its position, idea and persuade or even dissuade other parties into or out of taking certain actions. Given the outcome of the study, we recommend as follows:

i. Leadership should strive to be more amoebic, flexible and open towards seeming differences in relationships especially as obtainable within a context where the interested parties can be considered as significant to the extent that their actions or inactions hold severe implications for the overall functioning of the system or organization.

ii. Organizational goals and their corresponding strategies should be communicated clearly and through recognized formal channels, allowing for feedback and correspondence with various stakeholders and would-be affected parties or groups

iii. Consultative forums should be designed to allow and provide for collaboration, group participation and strengthening of ties and relations between leaders and the organizations' stakeholders especially given the democratic dispensation of most organizations today. The support of organizational members is a critical element for leader effectiveness.

\section{References}

[1]. Ahiauzu, A.I \& Asawo, S.P (2016). Advanced social research methods. A CIMRAT publication.

[2]. Childre, D. L., \& Cryer, B. (2000). From chaos to coherence: The power to change performance (2 ${ }^{\text {nd }}$ ed.). Boulder Creek, CA: Planetary

[3]. Cole, G.A. (2000). Management theory and practice London. Ashford Colour Press.

[4]. Donati P (2009). What does subsidiarity mean? The relational perspective.Journal of Markets and Morality, 12(2) 211-243.

[5]. Donati P (2011). Relational sociology: A new paradigm for the social sciences. Abingdon: Routledge.

[6]. Ewurum,L.(2007). Leaders on leadership.Sunday Sun (Lagos). 21, January, 53.

[7]. Flanagan, J. (1954). The critical incident technique.Psychological Bulletin, 51(4), 327 - 358

[8]. Grant, C. \&Osanloo, A. (2014) Understanding, selecting, and integrating a theoretical framework in dissertation research: Creating the blueprint for your house.Adinistration Issues Journal. 4(2) $12-26$

[9]. Hogan, R. \& Kaiser, R.B. (2005). What we know about leadership. Review of General Psychology, 9 (2), 169 - 180. DOI: $10.1037 / 1089-2680.9 \cdot 2.169$

[10]. Holmes, M (2011). Emotional reflexivity in contemporary friendships. Understanding it usingelias and facebook etiquette. Sociological Research Online; 16(1) 11

[11]. Inyang, B.J (2004). Management theory, principles and practice.Calabar: Merb Publishers.

[12]. Jacobs, L. (1992) Insights from psychoanalytic self-psychology and Intersubjectivity theory for gestalt therapists. The Gestalt Journal; 15 (2)

[13]. Madni, A.M (2007) Designing for resilience. ISTI lecture notes on advanced topics in systems engineering

[14]. Nagata, A. L (2004) Promoting self-reflexivity in intercultural education.Journal of intercultural communication; 139 - 167

[15]. Njoku, R. (2004). Political education for Nigerian citizens. Aba: Cheedal Global prints. 
[16]. Njoku, R. (2008). Administrative management, Aba: Cheedal Global Prints Ltd

[17]. Njoku, R. (2013). Human capital management, Aba: Nwachukwu Print.

[18]. Northouse, P. G. (2013). Leadership: Theory and practice. New Delhi: Sage.

[19]. Ogbeidi, M. (2012). Political leadership and corruption in Nigeria since 1960: A social economic analysis; Journal of Nigeria Studies; 1 (2) 1-25

[20]. Okafor, E. (2013). Leadership and productivity in Nigeria: Implications for work organisations and national development. Jorind 11(1)

[21]. Pearce C.L.\& Conger J.A. (2003). Shared leadership: Reframing the hows and whys of leadership. Thousand Oaks, CA: Sage.

[22]. Peters, F. (2013).Theories of consciousness as reflexivity.The Philosophical Forum; 44, 341 - 372

[23]. Petty, R.E., Fabrigar, R.L \& Wegener, D (2003) Emotional factors in attitudes and persuasion. In R. J. Davidson, K.R. Scherer, \& H. H. Goldsmith (Eds), Handbook of affective sciences (pp. 752 - 772), Oxford: Oxford University Press.

[24]. Reave, L. (2005). Spiritual values and practices related to leadership effectiveness. The Leadership Quarterly, 16:655-687.

[25]. Rosenberg. M (1990) Reflexivity and emotions.Social Psychology Quarterly, 53 (1), 3-12.

[26]. Ryan, M. R. \& Deci, E. L. (2000). Intrinsic and extrinsic motivation: Classic definition end new directions. Contemporary Educational Psychology, 25 (19), 54-67.

[27]. Ryan, R. M., \& Deci, E. L. (2003). On assimilating identities to the self: A self-determination theory perspective on internalization and integrity within cultures. In M. R. Leary \& J. P. Tangney (Eds.), Handbook of self and identity: 253-272. New York: Guilford.

[28]. Umoh, G.I., Amah, E., \& Wokocha, H.I (2014) Management development and organizational resilience. A case study of some selected manufacturing firms in Rivers State. Nigeria. IOSR Journal of Business and Management, 16(2) 7 - 16

[29]. Urim, U. M. (2009).Teamwork and leadership.Being a seminar paper presented at the M.Sc. class, Department of Sociology, Human Resource Management and Industrial Relations unit, OlabisiOnabanjo University, Ago-Iwoye, Ogun State.

[30]. Usó-Doménech, J.L \& Nescolarde-Selva, J (2016).What are belief systems? Foundations of Science, 21 (1), 153-175

[31]. Weaver, E. (2013). Desistance, reflexivity and relationality. European Journal of Probation University of Bucharest. $5(3) 71-88$

[32]. Yukl, G. (2011). Leadership in organizations. New Delhi: Dorling Kindersley (India).

[33]. Zeb-Obipi, I (2007). Analysis of organizational action: The use of definitional and explanatory constructs. West African Journal of Business, 9(1).

[34]. Zeb-Obipi, I (2016). Lecture notes on advanced organizational behaviour and applications. Department of Management, Faculty of Management Sciences, Rivers State University of Science and Technology. 